\title{
The Research of Comprehensive Evaluation Method in the Application of Professional Courses
}

\author{
Haihong Li \\ College of Mechanical Engineering, Taiyuan University of Science and Technology, Tai Yuan \\ 030024, China \\ lihaihongty@sina.com
}

Keywords: comprehensive evaluation method, examination mode of course, college education.

\begin{abstract}
The examination mode of course is determined by the teaching contents, teaching methods and teaching purpose, while it also has an important effect on the teaching. In order to promote the learning of professional courses, this paper explores the evaluation ways of mechanical and electrical professional course. It analyses the way of comprehensive evaluation of the role of the professional courses and puts emphasis on practice to evaluate the condition of knowledge important role. It results a comprehensive evaluation method which is useful to other professional course to give the performance evaluation.
\end{abstract}

\section{Introduction}

Curriculum evaluation is based on certain criteria and methods for students to evaluate the effect of cognitive process. Evaluation ways, evaluation methods, evaluation content, and assessment standard not only affects the teacher's teaching method and teaching attitude, at the same time on the depth of the students' learning style, thinking and even learning experience also has significant guiding role. A Wang [1] Used statistical methods to examine the influence of the causal relationship of different "check method" between the teacher's "evaluation of teaching level" and "student achievement", and the "check method" was used to do inspection for the influence of "students' evaluation of teaching". The result shows that the "student achievement" and "students' evaluation of teaching" minimal positive correlation coefficient; "check method" of courses and "students' evaluation of teaching" a significant negative correlation relationship, and has nothing to do with the students' test scores. The main research was how to do the fairness of the appraisal method and the correct understanding and evaluation of teachers' teaching level, but the conclusion showed that the evaluation mode of "teaching" and "learning" exist important role in the unity of opposites at the same time.

Given the important role, the examination way has been exploration and reformed since ancient times. With the knowledge and knowledge carrier updated, the teaching contents and teaching methods have to keep pace with the times, so the final appraisal way of evaluation of teaching effect need for new knowledge and new ways to improve their own evaluation system. So a lot of education researches on curriculum evaluation method are discussed, such as advice to introduce western teaching experience [2].Not only that, similar to their aptitude, evaluation system also needs to differ, the different ways of teaching form is for different evaluation. And with the hot issues in the current education reform, such as the autonomous learning ability training and practical teaching, etc., are also corresponding evaluation method have been proposed [3]-[4].In the botanical garden specialized as object, Jing-hui Xia [5] analyses the characteristics of the skills courses in applied undergraduate teaching, gives a systematic way of assessment of a proportion and score. The literature on the evaluation of the professional course is relatively comprehensive analysis and professional teachers should learn and think. On this basis, the study on mechanical engineering curriculum evaluation is analyzed, and designs a comprehensive evaluation system for examination course grades. 


\section{The research objective of professional courses examination method}

Colleges and universities has the responsibility to training demand of talents for the society, so with the changing of social demand, higher education will need to adjust to ensure and social needs. Currently, unit of choose and employ persons pay more attention to the talent comprehensive quality and practical ability, so strengthen the student beginning ability in the teaching and the cultivation of vocational skills is particularly important.

The importance of practice has been approved by the education system, and this part can be in ads to the course with the practical condition, including foundation courses and professional courses. But the most relevant to professional demand, can best embody the professional skill and the employment units are concerned about is the professional practice of the course. Compared with basic course, professional course can reflect the comprehensive ability of personal and professional accomplishment.

There are two aspects have to be researched of colleges and universities because of unit of choose and employ persons pay most attention to student's professional course learning content and grasp. At first, constantly modify the training plan and teaching outline with the development of science and technology. Second, as much as possible to establish a scientific and reasonable learning evaluation system to fully reflect the students' learning. The first research has become the basic the institutionalization of the work, the second research for the most part by traditional examination way. Examination form, either for the teachers, the assessment results shall be used to objective evaluation of students mastery of knowledge, for students, examination content is around the center of learning, for unit of choose and employ persons, it is an instrument of understand students' knowledge category, also is the basis for choice of choose and employ persons. So, curriculum evaluation plays a more important role from the employment point of view.

\section{Examination Question and Reason}

The major-course examination at present mainly has two forms: test and examination. Exam course is choose paper form, which according to the teaching material, teaching outline, and exam covers of the proportion of the syllabus, then grades students according to the final question paper. At present, even if the test in the form of specialized courses and the practice, but in the final score standard, the question paper grades are usually not less than $70 \%$, removing the peacetime grades, the practice is about $10 \%$.

And the other broad categories examines the nature of the course, as a result of the school and the teachers' different teaching links, standard also does not agree to the points, but most of the practice of score in line with the proportion of test classes.

In the traditional examination way, the score of practice in the assessment results is low and the great proportion is the inadequate infrastructure of education in a long period of time. Less equipment, especially the professional practice of the course, long-term funding investment insufficiency, and there are too much students participating in trials, failed to meet the effect of student independently complete the practice, result in practice is not easy to distinguish students' practical ability, so can't put the performance evaluation as the dominant practice.

As the recognition of the importance of practice, as well as the improvement of the education system, speed up the pace of the construction of laboratory, especially specialized laboratories, the hardware facilities of the practice is the basic guarantee. Although a professional course, relevant experimental equipment with situation also basic can meet the needs of students' practice, become acknowledge platform for students to display individual integrated ability. In this case, for students, must be finished independently practice, it requires students to have to understand and apply what they have learned, there is no chance to fish in troubled waters. For practice teachers, the results given can also more accurately reflect the student's practice of conform to requirements.

Since the practice result is enough fair to evaluation of students' skill level than ever before, the ratio of its traditional score is need further modification, to adapt to the new teaching environment. Of 
course, how many changed also need to modify a scientific research process, so as to give reasonable suggestions.

\section{Establish a comprehensive scoring system}

As a result of the exam course changes proportion involving many factors, so to modify the reasonable value of the practice achievement of scale research, might as well begin with specialized courses for examination.

At the same time, increase the proportion of practice you will first need to acquire a correct practice. But how to obtain practical result, this article to follow ability tests as the center and the principle of paying equal attention to knowledge and skills, to design a scoring system research, and put forward the following ideas:

\subsection{Practice content by man.}

Students choose training content by themselves, it meaning that according to the course content, their own willingness to obtain employment, consult practice project and put forward the need to practice content, then the teacher according to the project selected by the student to group training.

The advantage of this approach is to increase students' initiative to enhance their professional skills and ability. But its drawback is that a significant increase in the practice of teachers' workload. For solve it can choose professional teachers to participate in the students practice.

As the professional teachers need have general ability to professional courses. On this basis, after the students choose their practice project, different projects can be let different teacher for guidance if they are grouped. With reference to the current curriculum design standard of determining student group number, it can guarantee teacher give an objective evaluation and ensure students to get more comprehensive and better guide targeted professional knowledge at the same time.

On the other hand, although professional teachers intervention in the course of the professional practice only a few hours, but it can offer important reference significance on the content of the course design and graduation design.

\subsection{Update the inspection form.}

The traditional examination forms mainly include attendance at ordinary times, the practice report and test question paper. In those forms, question paper is simplification from the practicality, explore and the demand of autonomy of professional courses. From the point of the current evaluation, practice report is mostly the accumulation of basic knowledge, lack of subjective evaluation. Practice of students is according to the teacher and practice instruction steps to test, lack of independent thinking and process supervision. If you want to play the inspection in the cultivation of talents and teaching enthusiasm, it still need to explore new forms of assessment, such as independent features and research reports, etc.

Independent display is hope to student give explain of obtain knowledge or product design include physical and software from the projects choose by themselves, and explain from not constrained by paper reports or PPT. Report is a description of how to get the practical results under the theory foundation or fixed design system. Independent display is a publicity for their achievements at first and then is the introduction of the basic theory and practical technology to support the correctness of the practical results.

For example, in the practice of numerical control technology course, students need to introduction the function, characteristics, applicable of the system at first, then is the development platform and key statements. Through the process of students' independent display, the content of practice project and master degree will be given more objective results.

Independent reporting idea transformation is not only the order of content adjustment, more important is thinking transformation. From the employment point of view, the introduction way of the students from "what did I learn anything, so I'll do" converted to "what I do, because I learned what". In subjective, also make the students from "I didn't learn anything, so I won't do" into "I'm not going to do, because I haven't learned anything", so as to stimulate students "so I should go to learn what". 
The train of thought transformation also has positive significance to improve the students' autonomous learning.

\subsection{Score proportion of modification.}

Comprehensive evaluation system on the basis of source: attendance at ordinary times, to complete the student's attendance discipline management, suggest that accounted for $10 \%$;Practical operation process, used for mandatory requirements for basic skills, is the score of actual operation, suggest that accounted for $10 \%$;Practice report is for students to consolidate knowledge, summary of training skills, suggested that accounted for $10 \%$; The traditional paper-based test, used to force on the basic knowledge, suggest that accounted for 30\%; Independent display report, the embodiment of the comprehensive cognition and skills, suggested that accounted for 30\%; And the learning process of proof material, it is suggested that accounted for $10 \%$.
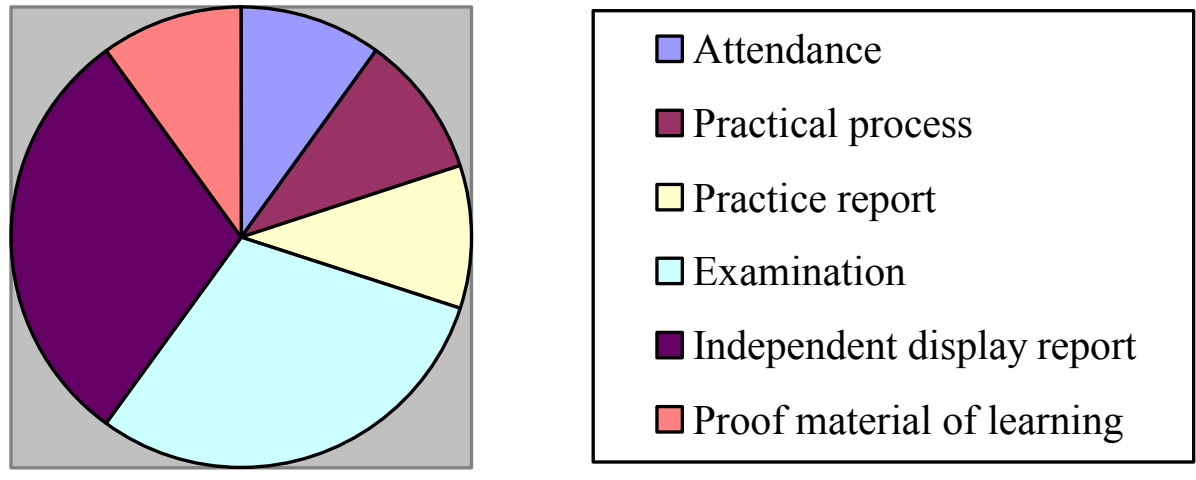

Fig. 1 Score proportion of the comprehensive evaluation method

More than the proportion of each link can be based on the characteristics of professional courses teachers in the process of teaching this course.

\section{Summary}

Through to the professional course teaching characteristic, in view of the test class grades without related on the basis of the status quo, this paper examines the specialized courses related problem analysis and comprehensive evaluation system of the design specification, and give the suggestion with rating scale, comprehensive evaluation system have certain reference significance to the appraisal of such courses.

\section{References}

[1] A WAN, Zhi-xin ZHANG, Shi-jin YU, et al. The influence of assessment methods on college students' evaluation of teaching. Journal of Teachers College (Social Science Edition). Vol. 33(2014) No. 3, p.152-154.

[2] Ai-ying Yang, Yang Song. On reform of assessment models in higher education. Journal of Changzhou Vocational College of Information Technology. Vol. 8(2009) No. 2, p.19-20.

[3] Hui-hui He. The research on the self-study exam comprehensive reform pilot of practice course procedural appraisal. Science \& Technology Vision. Vol. 29 (2013), p.15-16.

[4] Jianqiang Wu, Yan Li, Feng-yan Qi. The open experiment teaching, autonomous learning mode exploration and practice of assessment ways. China University Teaching. Vol. 4 (2011), p.70-72.

[5] Jing-hui Xia. On reform of skill course evaluation methods in practical undergraduate teaching. Journal of Southwest China Normal University (Natural Science Edition). Vol. 38 (2013) No.6, p. 193-196. 